\title{
STUDI KUALITATIF TENTANG PERAN KEPALA PUSKESMAS DI KABUPATEN TANJUNG JABUNG BARAT TERHADAP PENINGKATAN MUTU PELAYANAN KESEHATAN DI PUSKESMAS
}

\author{
The Role of Head of Public Health Centre on The Quality of Health Services in West \\ Tanjung Jabung Regency: A Qualitative Study
}

\author{
Andy Amir ${ }^{1}$, Dwi Noerjoedianto ${ }^{1}$, Herwansyah ${ }^{1}$ \\ ${ }^{1}$ Program Studi Ilmu Kesehatan Masyarakat, FKM Universitas Jambi
}

\begin{abstract}
Abstrak
PUSKESMAS sebagai salah satu fasilitas kesehatan tingkat pertama menyediakan berbagai pelayanan kesehatan dasar bagi masyarakat. Keberadaan PUSKESMAS di setiap wilayah kerja dalam rangka mendukung pencapaian derajat kesehatan masyarakat yang setingi-tingginya melalui upaya kesehatan masyarakat. Pelayanan kesehatan yang disediakan oleh PUSKESMAS kepada masyarakat meliputi perencanaan, pelaksanaan, evaluasi, pencatatan dan pelaporan. Seluruh komponen pelayanan kesehatan dasar di PUSKESMAS ini selanjutnya diatur dalam suatu sistem. Penelitian ini bertujuan untuk melihat sejauh mana Peran Kepala PUSKESMAS dalam Upaya Peningkatan Mutu Pelayanan Kesehatan. Jenis penelitian ini adalah penelitian kualitatif dengan melibatkan 16 orang pimpinan PUSKESMAS yang ada di Kabupaten Tanjung Jabung Barat. Hasil penelitian menunjukkan bahwa mayoritas informan memiliki masa kerja diantara 6-15 tahun, tingkat pendidikan Sarjana/Profesi, dan telah mengikuti pelatihan manajemen PUSKESMAS. Dapat dideskripsikan bahwa informan mampu menceritakan tentang tahapan perencanaan program kegiatan di PUSKESMAS dengan melibatkan beberapa staf yang terkait. Informan juga mampu menjelaskan begaimana mekanisme pengambilan keputusan, khususnya yang berhubungan dengan pelaksanaan pelayanan di PUSKESMAS. Para kepala PUSKESMAS berupaya untuk meningkatkan kemampuan kepemimpinan, karena setiap orang memiliki gaya kepemimpinan yang berbeda.
\end{abstract}

Kata Kunci: Peran, Kepala PUSKESMAS, Mutu Pelayanan

\begin{abstract}
Public Health Centres (PHC) is considered as the first health facilities, which are able to provide basic health services to the community. PHC plays important roles, especially attaining proper public health services in order to support the Government program to increase public health status. The services may include planning, action, evaluation, registration, and reporting. This study aims to explore the role of head of PHC in increasing the quality of PHC services in many ways. This is a qualitative study which involved 16 head of PHCs in West Tanjung Jabung Regency. Data was collected from in-depth interviews, and was transcribed into transcripts. The data was then analysed using content analysis. The results describes that head of PHCs are able to explain their role in terms of planning, actuating, decision making, motivation and leadership. However, the characteristics of leadership differ from each other; therefore, this leads to the different of quality of expected outputs.
\end{abstract}

Keywords: Role, Head of PHC, Quality of Services

Korespondensi : Herwansyah

Email : herwansyah.unja@gmail.com

\section{PENDAHULUAN}

Badan Kesehatan Dunia (World Health Organization) telah mengeluarkan berbagai kebijakan yang berorientasi kepada kesehatan masyarakat. Regulasi dan kebijakan ditujukan untuk memenuhi salah satu hak dasar manusia, yaitu hak untuk memperoleh pelayanan kesehatan yang menyeluruh, terjangkau dan memadai. Selain itu, institusi kesehatan dunia ini merekomendasikan berbagai kebijakan kepada negara-negara di dunia untuk mempersiapkan segala hal yang berhubungan dengan pencapaian derajat 
kesehatan masyarakat yang maksimal. ${ }^{1}$ Salah satu rekomendasi tersebut adalah kebijakan tentang Universal Health Coverage (UHC) yang diimplementasikan melalui pelayanan kesehatan primer, sekunder maupun tersier. ${ }^{2}$ Walaupun setiap negara di dunia memiliki karakteristik yang berbeda, kebijakan global ini dapat diaplikasikan dengan mengadopsi regulasi yang dikeluarkan oleh Badan Kesehatan Dunia.

Target untuk mencapai UHC memerlukan keseriusan peran Pemerintah setiap negara di dunia untuk menjamin aspek pendukung tercapainya UHC. Penguatan sistem kesehatan harus dilaksanakan dalam rangka menjamin setiap masyarakat di dunia mendapatkan pelayanan kesehatan yang sesuai dengan standar. Berbagai peran pemerintah dapat tercermin pada penyedian fasilitas infrastruktur kesehatan masyarakat, Sumber Daya Manusia di bidang kesehatan, dan penyedian jaminan kesehatan nasional untuk pembiayaan kesehatan. Masingmasing negara di dunia memiliki sistem yang berbeda dalam menimplementasikan kebijakan ini. Sebagian negara memprioritaskan kejelasan hukum di bidang kesehatan dibandingkan dengan menyusun sistem kebijakan kesehatan. Akan tetapi, setiap negara mempertimbangkan beberapa aspek untuk mewujudkan UHC, diantaranya: memberi batasan kelompok penerima skema asuransi kesehatan; (2) membuat peraturan tentang penyedia layanan kesehatan dasar; (3) sistem pembiayaan kesehatan; dan (4) membangun fasilitas kesehatan. ${ }^{1}$

Salah satu aspek pendukung terwujudnya UHC adalah penyedian layanan kesehatan kepada masyarakat. Berdasarkan Peraturan Menteri Kesehatan
Nomor 71 Tahun 2013, pelayanan kesehatan kepada masyarakat dapat diakses melalui fasilitas kesehatan tingkat pertama, seperti Pusat Kesehatan Masyarakat (PUSKESMAS), praktek dokter swasta, klinik milik pemerintah/milik swasta; pelayanan kesehatan rujukan, seperti Rumah Sakit milik pemerintah/milik swasta. Selanjutnya regulasi ini juga mengatur hak masyarakat untuk mendapatkan pelayanan kesehatan yang mencakup pelayanan yang berorientasi pada pencegahan dan promosi, pengobatan dan penyediaan layanan rehabilitasi, serta penyediaan obat-obatan sesuai dengan kebutuhan masyarakat. ${ }^{3}$

PUSKESMAS sebagai salah satu fasilitas kesehatan tingkat pertama menyediakan berbagai pelayanan kesehatan dasar bagi masyarakat. Keberadaan PUSKESMAS di setiap wilayah kerja dalam rangka mendukung pencapaian derajat kesehatan masyarakat yang setingi-tingginya melalui upaya kesehatan masyarakat. Peraturan Menteri Kesehatan Nomor 75 Tahun 2014 mengatur bahwa upaya kesehatan masyarakat dilakukan untuk memelihara dan meningkatkan derajat kesehatan masyarakat melalui upaya pencegahan dan menanggulangan berbagai permasalahan kesehatan berbasis keluarga, kelompok dan masyarakat. Selain itu, komponen pelayanan kesehatan juga diatur di dalam peraturan ini. Pelayanan kesehatan yang disediakan oleh PUSKESMAS kepada masyarakat meliputi perencanaan, pelaksanaan, evaluasi, pencatatan dan pelaporan. Seluruh komponen pelayanan kesehatan dasar di PUSKESMAS ini selanjutnya diatur dalam suatu sistem. ${ }^{4}$

Akan tetapi, pemanfaatan PUSKESMAS sebagai fasilitas kesehatan tingkat pertama oleh masyarakat masih 
tergolong rendah. Data dari Kementerian Kesehatan menunjukkan bahwa proporsi kunjungan masyarakat ke PUSKESMAS hanya berkisar 33\%. ${ }^{5}$ Berdasarkan data dari Kementarian Kesehatan menunjukkan bahwa Provinsi Jambi pada tahun 2017 memiliki 186 PUSKESMAS, dengan rasio antara PUSKESMAS dan Kecamatan adalah 1,32. Dengan kata lain, 1 PUSKESMAS sudah tersedia di setiap Kecamatan. ${ }^{6}$ Akan tetapi, diantara 186 PUSKESMAS yang ada, hanya 30 PUSKESMAS se-Provinsi Jambi yang memberikan pelayanan kesehatan sesuai standar. Dilihat dari proporsi, sekitar $84 \%$ PUSKESMAS yang ada belum menyediakan pelayanan kesehatan yang maksimal dan sesuai standar kepada masyarakat. Fenomena ini berbanding terbalik dengan kondisi PUSKESMAS yang telah terakreditasi oleh Komisi Akreditasi Fasilitas Kesehatan Tingkat Pertama (FKTP), dimana sebesar 54\% PUSKESMAS di Provinsi Jambi telah terakreditasi. Seharusnya kondisi FTKP yang telah terakreditasi ini telah mampu menyediakan pelayanan kesehatan sesuai standar, karena setiap FTKP telah menyusun dokumen Standar Operasional Prosedur (SOP) pelayanan. ${ }^{7}$

Berbagai teori tentang mutu pelayanan di bidang kesehatan menjelaskan bahwa berbagai faktor yang berhubungan dengan tinggi rendahnya mutu pelayanan kesehatan yang diberikan oleh fasilitas kesehatan dasar. Beberapa faktor tersebut diantaranya adalah penyedia pelayanan kesehatan, faktor organisasi dan kepemimpinan, dan faktor lingkungan (internal dan eksternal). Dari sisi kepemimpinan, kualitas pelayanan kesehatan dapat didukung oleh dukungan pemimpin, perencanaan yang baik, pendidikan dan pelatihan serta manajemen yang efektif tentang sumber daya, tenaga kesehatan dan proses. ${ }^{8}$

Berdasarkan uraian latar belakang di atas, maka tim peneliti tertarik untuk meneliti tentang mutu pelayanan kesehatan di PUSKESMAS dilihat dari peran pimpinan PUSKESMAS dalam berbagai komponen penyediaan pelayanan kesehatan dasar bagi masyarakat.

\section{METODE}

Penelitian ini merupakan penelitian kualitatif dengan disain penelitian explorative study untuk menggali informasi dari informan tentang peran yang telah dilakukan dalam peningkatan mutu pelayanan kesehatan di PUSKESMAS

Sampel dalam penelitian ini adalah seluruh kepala PUSKESMAS yang ada di Kabupaten Tanjung Jabung Barat yang berjumlah 16 orang.

Analisis data diolah dengan teknik content analysis. ${ }^{9}$ Tim peneliti menggunakan panduan pertanyaan, lembar observasi dan kuesioner yang dikembangkan dari penelitian-penelitian sebelumnya tentang peran kepala PUSKESMAS dalam upaya peningkatan kualitas pelayanan kesehatan di PUSKESMAS.

\section{HASIL DAN PEMBAHASAN Perencanaan}

Hasil penelitian menunjukkan bahwa kepala PUSKESMAS telah mampu menjelaskan dengan baik peran perencanaan yang telah dilakukan. Baik perencanaan yang bersifat strategis maupun perencanaan rutin yang akan dilakukan setiap tahunnya. Salah satu informan menjelaskan sebagai berikut:

“.........tentu sebagai pimpinan saya harus mampu menunjukkan peran melibatkan semua staf terkait dalam proses 
perencanaan di PUSKESMAS ini. Ya.walaupun ada yang sifatnya sangat penting dan strategis, saya tetap harus melibatkan staf."

Pentingnya peran di bidang perencanaan juga dipahami sebagai salah satu unsur yang penting dalam kepemimpinan seorang kepala PUSKESMAS. Perencanaan dinilai penting karena merupakan proses penentuan tujuan atau sasaran yang hendak dicapai dan menetapkan jalan dan sumber yang diperlukan untuk mencapai tujuan itu seefisien dan seefektif mungkin. Salah satu informan memberikan penjelasan sebagai berikut:

"Perencanaan itu sangat penting dilakukan. Apalagi kita telah Akreditasi. Proses akreditasi mengajarkan kami untuk melakukan perencanaan dengan baik sehingga nanti hasil yang diharapkan akan maksimal memenuhi kebutuhan masyarakat."

Rangkaian tindakan atau kegiatan perencanaan yang dilakukan oleh Kepala PUSKESMAS perlu dilakukan karena dua alasab, pertama, untuk mewujudkan kemajuan atau keberhasilan sesuai dengan apa yang diinginkan, kedua, supaya tidak terjadi hal-hal yang tidak diharapkan, kondisi yang sama atau lebih rendah dari pada keadaan saat ini.

\section{Actuating}

Informan mendefinisikan peran ini sebagai suatu tindakan untuk mengusahakan agar semua anggota kelompok berusaha untuk mencapai sasaran yang sesuai dengan perencanaan manejerial dan usaha-usaha organisasi. Dengan kata lain, menggerakkan orang-orang agar mau bekerja dengan sendirinya atau dengan kesadaran secara bersama-sama untuk mencapai tujuan dikehendaki secara efektif.
Salah satu informan memberikan tanggapan sebagai berikut:

“...hmmm ini yang sangat menantang untuk dilakukan. Karena menurut saya, menggerakkan staf untuk memiliki semangat meningkatkan kualitas pelayanan itu harus dengan seni. Sehingga pada saat ada suatu kondisi tanpa pimpinan, mereka dapat menyelesaikan secara mandiri. Karena dinilai telah memahami peran dan tugas masing-masing staf."

Perbedaan kondisi PUSKEMAS sangat berpengaruh terhadap peran pimpinan. Dalam hal ini yang dibutuhkan adalah kepemimpinan. Actuating adalah pelaksanaan untuk bekerja. Untuk melaksanakan secara fisik kegiatan dari aktivitas tesebut, pimpinan mengambil tindakan-tindakannya kearah itu. Seperti : Leadership (pimpinan), perintah, komunikasi dan conseling (nasehat). Actuating disebut juga" gerakan aksi “ mencakup kegiatan yang dilakukan seorang manager untuk mengawali dan melanjutkan kegiatan yang ditetapkan oleh unsur-unsur perencanaan dan pengorganisasian agar tujuan-tujuan dapat tercapai.

\section{Pengambilan Keputusan}

Pengambilan keputusan dapat dianggap sebagai suatu hasil atau keluaran dari proses mental atau kognitif yang membawa pada pemilihan suatu jalur tindakan di antara beberapa alternatif yang tersedia. Setiap proses pengambilan keputusan selalu menghasilkan satu pilihan final. Keluarannya bisa berupa suatu tindakan (aksi) atau suatu opini terhadap pilihan.

Pengambilan keputusan yang didasarkan atas intuisi atau perasaan memiliki sifat subjektif sehingga mudah terkena pengaruh. Pengambilan keputusan 
berdasarkan intuisi ini mengandung beberapa keuntungan dan kelemahan. Pimpinan PUSKESMAS mampu membaca situasi yang ada dalam proses pengambilan keputusan, sehingga putusan yang diambil berdasarkan kondisi yang ada. Salah satu informan menjelaskan sebagai berikut:

" Kami Pak, di PUSKESMAS yang sangat jauh dari keramaian. Wilayah kerja sangat luas, staf juga terbatas karena sangat jauh dari domisili. Pengambilan keputusan yang saya lakukan harus memikirkan kondisi mereka, tidak bisa hanya berdasarkan aturan dari Kabupaten saja."

Pengambilan keputusan yang berdasarkan logika adalah putusan yang rasional terhadap semuan unsur pada setiap sisi dalam proses pengambilan keputusan. Pada pengambilan keputusan yang berdasarkan rasional, keputusan yang dihasilkan bersifat objektif, logis, lebih transparan, konsisten untuk memaksimumkan hasil atau nilai dalam batas kendala tertentu, sehingga dapat dikatakan mendekati kebenaran atau sesuai dengan apa yang diinginkan. Pada pengambilan keputusan secara logika terdapat beberapa hal yang perlu diperhatikan, kejelasan masalah, orientasi tujuan (kesatuan pengertian tujuan yang ingin dicapai), pengetahuan alternatif (seluruh alternatif diketahui jenisnya dan konsekuensinya), preferensi yang jelas (alternatif bisa diurutkan sesuai criteria) dan hasil maksimal (pemilihan alternatif terbaik didasarkan atas hasil ekonomis yang maksimal).

\section{Kepemimpinan dan Motivasi}

Pemimpin PUSKESMAS mampu mendefinisikan motivasi sebagai karakteristik berorientasi pada tujuan yang membantu seseorang mencapai tujuannya. Ini mendorong seseorang untuk bekerja keras dalam mencapai tujuannya. Seorang eksekutif harus memiliki sifat kepemimpinan yang tepat untuk memengaruhi motivasi. Namun, tidak ada cetak biru khusus untuk motivasi. Salah satu informan memberikan tanggapan sebagai berikut:

"Sebagai seorang pemimpin, seseorang harus menjaga perspektif terbuka tentang sifat manusia. Mengetahui berbagai kebutuhan bawahan tentu akan membuat proses pengambilan keputusan lebih mudah."

Pimpinan PUSKESMAS mampu menyelaraskan dan mencocokkan kebutuhan bawahan dengan kebutuhan organisasi. Sebagai seorang pemimpin, eksekutif harus memastikan bahwa pelayanan kesehatan harus memiliki moral dan etika yang sama dengan yang ia cari dalam diri karyawannya. Dia harus memastikan bahwa bawahannya didorong dan dilatih dengan cara yang memenuhi kebutuhan bisnis.

Apresiasi dan penghargaan adalah motivator kunci yang memengaruhi seseorang untuk mencapai tujuan yang diinginkan. Menghargai perilaku yang baik dengan sedikit apresiasi, sertifikat, atau surat bisa menjadi motivator yang hebat. Jika sertifikat diberikan kepada seseorang, itu harus menyebutkan tindakan tertentu atau kualitas yang diberikan kepadanya. Salah satu informan menjelaskan sebagai berikut:

"Biasanya saya sering mengirimkan beberapa staf saya ke beberapa pelatihan ke luar kota. Selain untuk belajar, ini saya lakukan untuk menghargai pekerjaan yang telah mereka kerjakan. Supaya ada proses penghargaan atas perilaku positif kerja yang ditunjukkan oleh staf."

Menjadi panutan juga merupakan motivator utama yang memengaruhi orang 
dalam mencapai tujuan mereka. Seorang pemimpin harus memberikan contoh yang baik untuk memastikan orang-orangnya tumbuh dan mencapai tujuan mereka secara efektif. Mendorong individu untuk terlibat dalam perencanaan dan prosedur penyelesaian masalah penting tidak hanya memotivasi mereka, tetapi juga mengajarkan seluk-beluk faktor-faktor pengambilan keputusan utama ini. Selain itu, ini akan membantu semua orang untuk mendapatkan pemahaman yang lebih baik tentang peran mereka dalam organisasi. Komunikasi akan tidak ambigu dan tentunya akan menarik pengakuan dan penghargaan dari pemimpin.

Selain itu, motivasi dan kepemimpinan yang handal juga tergambarkan dalam mengembangkan semangat ke staf agar berdampak besar pada kesejahteraan organisasi. Keadaan perasaan seseorang membentuk tatanan semangatnya. Tindakan dan keputusan seorang pemimpin memengaruhi semangat bawahannya. Karena itu, dia harus selalu sadar akan keputusan dan kegiatannya. Semangat tim adalah jiwa organisasi. Pemimpin harus selalu memastikan bawahannya menikmati melakukan tugas mereka sebagai tim dan menjadikan diri mereka bagian dari rencana organisasi.

\section{KESIMPULAN DAN SARAN}

Berdasarkan hasil penelitian yang telah dilakukan, diperoleh bahwa Kepala PUSKESMAS telah menjalankan tugas pokok dan fungsi sebagai pimpinan untuk meningkatkan mutu pelayanan kesehatan dasar di PUSKESMAS. Kepala PUSKESMAS telah melibatkan beberapa staf terkait dalam proses perencanaan kegiatan yang akan dilakukan, termasuk didalamnya perencanaan keuangan. Pemberian motivasi dan pergerakkan kepada setiap staf, dilakukan secara nyata dalam berbagai kesempatan, seperti pada saat apel pagi dan mini lokakarya. Sistem pengambilan keputusan yang diterapkan dengan melibatkan staf yang menjadi bagian dari program, akan tetapi ada beberapa keputusan yang diambil sendiri oleh pimpinan.

Peneliti memberikan masukan kepada Dinas terkait, dalam penunjukkan kandidat kepala PUSKESMAS harus berlandaskan beberapa kompetensi sebagai seorang pemimpin, khususnya mampu memahami menajemen PUSKESMAS. Selain itu, tipe kepemimpinan yang diterapkan seharusnya berdasarkan kondisi PUSKESMAS. Karena akan berbeda perlakuan PUSKESMAS dengan wilayah kerja yang sangat luas dan terpencil, dengan PUSKESMAS yang wilayah kerjanya terbatas dan berlokasi di pusat kota.

\section{DAFTAR PUSTAKA}

1. World Health Organization., 2018. Universal Health Coverage. Switzerland: World Health Organization.

2. Dye, C., Reeder, J.C. and Terry, R.F., 2013. Research for universal health coverage.

3. Kementerian Kesehatan, R.I., 2012. Sistem Kesehatan Nasional. Jakarta: Kementerian Kesehatan Republik Indonesia

4. Kementrian Kesehatan, R.I., 2014. Peraturan Menteri Kesehatan Republik Indonesia Nomor 75 Tahun 2014 Tentang Pusat Kesehatan Masyarakat (Puskesmas). Berita Negara Republik Indonesia Tahun 2014 Nomor 1676.

5. Kementerian Kesehatan RI., 2016. Peraturan Menteri Kesehatan Nomor 44. Tahun 2016 Tentang Pedoman Manajemen Puskesmas. Departemen 
Kesehatan Republik Indonesia, Jakarta.

6. Kementerian Kesehatan., 2017. Keputusan Menteri Kesehatan Republik Indonesia Nomor HK. 01.07/MENKES/85/2017 tentang Lokus Program Indonesia Sehat dengan Pendekatan Keluarga Tahun 2017.

7. Komisi Akreditasi FTKP., 2018. Akreditas Puskesmas. Jakarta: Kementerian Kesehatan Republik Indonesia.

8. Mosadeghrad, A.M., 2014. Factors influencing healthcare service quality. International journal of health policy and management, 3(2), p.77.

9. Sugiyono, 2009, Metode Penelitian Kuantitatif, Kualitatif, R\&D,Bandung: Rosdakarya. 